\title{
Programa Saúde na Escola: O que revelam as produções científicas na área de
}

\section{educação?}

\author{
Health at School Program: What do scientific productions in the area of education reveal? \\ Programa Salud en la Escuela: ¿Qué revelan las producciones científicas en el área de la \\ educación?
}

Recebido: 02/04/2021 | Revisado: 11/04/2021 | Aceito: 14/04/2021 | Publicado: 27/04/2021

\author{
André Leite de Farias \\ ORCID: https://orcid.org/0000-0001-6096-4619 \\ Universidade Católica de Brasília, Brasil \\ E-mail: andreleitedefarias@gmail.com \\ Valdivina Alves Ferreira \\ ORCID: https://orcid.org/0000-0002-2306-7465 \\ Universidade Católica de Brasília, Brasil \\ E-mail: valdivina5784@hotmail.com
}

\begin{abstract}
Resumo
Este artigo tem como objetivo analisar a produção científica sobre o Programa Saúde na Escola no período de 2014 a 2019, na área de educação. Para tanto, adotou-se pressupostos da pesquisa qualitativa. Quanto à abordagem, foram utilizados procedimentos metodológicos de pesquisa documental e bibliográfica, sobretudo por meio do Portal Capes e da plataforma Scielo. Os resultados mostraram duas teses e nove dissertações, classificadas por autor, instituição, ano de publicação, título da produção, bem como dois artigos científicos, classificados por autores, revista, ano de publicação, título de produção científica. A triangulação de dados levou em consideração os problemas de pesquisas estabelecidos pelos autores das produções científicas, o Decreto 6.286, de 5 de dezembro de 2007, que estabelece o Programa Saúde na Escola, e o aporte teórico. A partir do levantamento de teses e dissertações e de artigos científicos, percebeu-se o alcance das medidas educacionais tomadas pelo Estado brasileiro para promover a articulação intersetorial e universalizar o atendimento aos estudantes da rede escolar pública de educação básica por meio de ações de prevenção, promoção e atenção à saúde. Concluiu-se que as ações sugeridas nas pesquisas sobre o Programa Saúde na Escola podem contribuir para a formação integral e para a qualidade de vida do estudante, bem como pode colaborar com práticas de gestão que levem em consideração as potencialidades das ações intersetoriais previstas nesse programa. No entanto, esta investigação revelou a escassez de estudos científicos a respeito de pesquisas sobre as diferentes ações dispostas no Programa Saúde na Escola.
\end{abstract}

Palavras-chave: Programa saúde na escola; Saúde do estudante; Ensino; Educação.

\begin{abstract}
This paper aims to analyze the scientific production on the Health at School Program from 2014 to 2019, in the area of education. To this end, assumptions of qualitative research were adopted. As for the approach, methodological procedures for documentary and bibliographic research were used, especially through the Capes Portal and the Scielo platform. The results showed two theses and nine dissertations, classified by author, institution, year of publication, title of production, as well as two scientific articles, classified by authors, magazine, year of publication, title of scientific production. The triangulation of data took into account the research problems established by the authors of scientific productions, Decree 6,286, of December 5, 2007, which establishes the Health at School Program, and the theoretical contribution. From the survey of theses and dissertations and scientific articles, the scope of educational measures taken by the Brazilian State to promote intersectoral articulation and universal service to students in the public school system of basic education through preventive actions was realized. health promotion and care. It was concluded that the actions suggested in the research on the Health at School Program can contribute to the integral formation and to the quality of life of the student, as well as it can collaborate with management practices that take into account the potential of the intersectoral actions provided for in this program. . However, this investigation revealed the scarcity of scientific studies regarding research on the different actions available in the Health at School Program.
\end{abstract}

Keywords: Health at school program; Student health; Teaching; Education.

\section{Resumen}

Este artículo tiene como objetivo analizar la producción científica sobre el Programa Salud en la Escuela de 2014 a 2019, en el área de educación. Con este fin, se adoptaron supuestos de investigación cualitativa. En cuanto al abordaje, se utilizaron procedimientos metodológicos para la investigación documental y bibliográfica, especialmente a través del 
Portal Capes y la plataforma Scielo. Los resultados arrojaron dos tesis y nueve disertaciones, clasificadas por autor, institución, año de publicación, título de producción, así como dos artículos científicos, clasificados por autores, revista, año de publicación, título de producción científica. La triangulación de datos tuvo en cuenta los problemas de investigación establecidos por los autores de producciones científicas, el Decreto 6.286, de 5 de diciembre de 2007, que establece el Programa Salud en la Escuela, y el aporte teórico. A partir del relevamiento de tesis y disertaciones y artículos científicos, se comprendió el alcance de las medidas educativas tomadas por el Estado brasileño para promover la articulación intersectorial y el servicio universal a los estudiantes del sistema escolar público de educación básica a través de acciones preventivas promoción y atención de la salud. Se concluyó que las acciones sugeridas en la investigación sobre el Programa Salud en la Escuela pueden contribuir a la educación integral y la calidad de vida del estudiante, así como pueden colaborar con prácticas de gestión que tomen en cuenta el potencial de las acciones intersectoriales previstas en este programa. Sin embargo, esta investigación reveló la escasez de estudios científicos sobre investigaciones sobre las diferentes acciones disponibles en el Programa Salud en la Escuela.

Palabras clave: Programa de salud en la escuela; Salud del estudiante; Enseñando; Educación.

\section{Introdução}

A política pública educacional se relaciona às decisões que o Estado toma em temáticas atinentes à educação. Nesse cenário, tratar os limites e possibilidades da política educacional implica examinar o alcance das medidas educacionais tomadas pelo Estado brasileiro (Saviani, 2008, p. 7). Assim, a execução das políticas educacionais demanda a apropriação e o uso de diversos espaços sociais como as políticas de saúde, assistência social, as ações de mobilização para participação, na escola, de empresas, famílias, integrantes da sociedade civil, ações socioeducativas envolvendo a comunidade e os espaços públicos (Libâneo, 2016, p. 49).

Tendo em vista o papel de guias gerais exercido pelos princípios educacionais, estabeleceu-se a prática de inseri-los na Constituição do país (Saviani, 2013, p. 210). Desse modo, conforme disposto na Constituição Federal de 1988 (CF/1988), no caput do artigo 205, a educação, direito de todos e dever do Estado e da família, será promovida e incentivada com a colaboração da sociedade, visando ao pleno desenvolvimento da pessoa, seu preparo para o exercício da cidadania e sua qualificação para o trabalho (Brasil, 1988).

Com relação a isso, o inciso VIII do artigo $4^{\circ}$ da Lei de Diretrizes e Bases da Educação Nacional (LDB 1996) estabelece que o dever do Estado com a educação escolar pública será efetivado mediante a garantia de atendimento ao educando, em todas as etapas da educação básica, por meio de programas suplementares de material didático-escolar, transporte, alimentação e assistência à saúde (Brasil, 1996).

Desse modo, o Programa Saúde na Escola (PSE), instituído, no âmbito dos Ministérios da Educação e da Saúde, pelo Decreto Presidencial $n^{\circ}$ 6.286, de 5 de dezembro de 2007, possui a finalidade de contribuir para a formação integral dos estudantes da rede pública de educação básica por meio de ações de prevenção, promoção e atenção à saúde (Brasil, 2007). No entanto, a partir da implementação do PNE 2014-2024, o que nos revelam as pesquisas científicas sobre o Programa Saúde na Escola, na área de educação?

A partir desse contexto, o objetivo desta pesquisa foi analisar a produção científica em teses, dissertações e em artigos científicos sobre o Programa Saúde na Escola no período de 2014 a 2019. Uma vez que tal instrumento legal faz parte das medidas implementadas pelo Estado brasileiro para mitigar os danos à saúde do estudante, a relevância dessa temática está relacionada ao papel da escola como local ideal para executar ações de educação e saúde para garantia e ampliação da qualidade de vida do estudante.

\section{Metodologia}

Esta investigação adotou os pressupostos da pesquisa qualitativa. Nesse sentido, na pesquisa qualitativa, o investigador pode fazer alegações de conhecimento com base em coleta de dados emergentes abertos com o objetivo de desenvolver temas a partir dos dados (Creswell, 2007, p. 35). Assim, quanto à abordagem, foram utilizados procedimentos metodológicos de pesquisa 
documental e bibliográfica, sobretudo por meio do Portal Capes e da plataforma Scielo.

Ademais, deram suporte teórico à contextualização sobre o Programa Saúde na Escola os trabalhos desenvolvidos e publicados por: Libâneo (Políticas educacionais no Brasil: desfiguramento da escola e do conhecimento escolar, 2016); Saviani (O Plano de desenvolvimento da educação: análise do projeto do MEC, 2007; Política educacional brasileira: limites e perspectivas, 2008; A educação na Constituição Federal de 1988: avanços no texto e sua neutralização no contexto dos 25 anos de vigência, 2013); Carvalho (A saúde vai à escola: a promoção da saúde em práticas pedagógicas, 2015); Chiari et al. (Rede intersetorial do Programa Saúde na Escola: sujeitos, percepções e práticas 2018); Figueiredo, Machado e Abreu (A saúde na escola: um breve resgate histórico, 2010). Nesse sentido, a pesquisa envolveu a investigação da produção científica com base em levantamento e análise de teses e dissertações disponibilizadas no Portal Capes e na plataforma Scielo. O escopo da pesquisa compreendeu 2 teses e 9 dissertações defendidas no período de 2014 a 2019, bem como 2 artigos científicos publicados também nesse período.

O seguinte descritor foi utilizado: "programa saúde na escola". Além do refinamento da busca por ano (2014 a 2019), houve também o refinamento por grande área do conhecimento (ciências humanas), por área de conhecimento (educação), área de avaliação (educação) e área de concentração (educação). Envolveu também o levantamento de artigos científicos indexados à plataforma Scielo. Foram encontrados 2 artigos científicos publicados no período de 2014 a 2019. O descritor utilizado foi: “programa saúde na escola”. Além desse refinamento da busca por ano de publicação (2014 a 2019), também foram filtrados por ano de publicação (2014 a 2019), área temática (educação), assunto (educação) e tipo de literatura (artigo).

Como estratégia de validação dos resultados, foi utilizada a triangulação de dados coletados em legislação, principalmente sobre o Programa Saúde na Escola, em dissertações e teses e em artigos científicos, a fim de criar justificativa coerente para subsidiar o objetivo desta pesquisa. Quanto a isso, cumpre destacar que a triangulação, segundo Figaro (2014, p. 129), é uma abordagem metodológica que requer um desenho de pesquisa, cujo desenvolvimento pode contar com técnicas de recolha de dados diferentes. Desse modo, a triangulação foi realizada a partir da recolha de dados de teses e dissertações, artigos científicos e documentos públicos, principalmente o Decreto Presidencial n ${ }^{\circ} 6.286$, de 5 de dezembro de 2007, que institui o Programa Saúde na Escola.

\section{Resultados e Discussão}

A saúde do estudante é aspecto relevante da política educacional brasileira, consistindo em condição para viabilizar ações governamentais que assegurem a formação integral dos estudantes da rede pública de educação básica por meio de ações de prevenção, promoção e atenção à saúde, conforme estabelecido no Decreto n ${ }^{\circ} 6.286$, de 5 de dezembro de 2007, que institui o Programa Saúde na Escola (Brasil, 2007), e no Plano Nacional de Educação 2014-2024, Lei no 13.005, de 25 de junho de 2014 (Brasil, 2014). O Programa Saúde na Escola tem como base a articulação entre escola e a rede básica de saúde visando contribuir para a formação integral dos estudantes da rede pública de educação básica por meio de ações de prevenção, promoção e atenção à saúde (Chiari et al., 2018, p. 2).

O Plano Nacional de Educação 2014-2024 (PNE 2014-2024) estabeleceu outras importantes estratégias relacionadas à saúde do estudante, como a promoção da articulação intersetorial entre órgãos e políticas públicas de saúde e a universalização, mediante articulação entre os órgãos responsáveis pelas áreas da saúde e da educação, do atendimento aos estudantes da rede escolar pública de educação básica por meio de ações de prevenção, promoção e atenção à saúde (Brasil, 2014).

Nesta investigação, os resultados apresentaram duas teses e nove dissertações. Assim, a Tabela 1 mostra a quantidade de trabalhos científicos por ano e por tipo de pesquisa, se tese ou dissertação. 
Tabela 1: Distribuição de teses e dissertações defendidas de 2014 a 2019.

\begin{tabular}{lllllllllllllll}
\hline \multicolumn{1}{c}{ Descritor } & $\mathbf{2 0 1 4}$ & $\mathbf{2 0 1 5}$ & $\mathbf{2 0 1 6}$ & & $\mathbf{2 0 1 7}$ & & $\mathbf{2 0 1 8}$ & $\mathbf{2 0 1 9}$ \\
Tipo de produção & D & T & D & T & D & T & D & T & D & T & D & T \\
"programa saúde na escola" & 4 & 1 & 1 & 1 & 3 & 0 & 0 & 0 & 0 & 0 & 1 & 0
\end{tabular}

Legenda: Dissertação (D); Tese (T). Fonte: Portal Capes - organização própria.

A Tabela 1 mostrou que dissertações foram defendidas nos anos de 2014, 2015, 2016 e 2019 e que as teses foram defendidas nos anos de 2014 e 2015. Destaca-se que não foram defendidas teses e dissertações sobre o Programa Saúde na Escola nos anos de 2017 e 2018.

O Quadro 1 mostra as duas teses encontradas após o refinamento, em que as seguintes informações são exibidas: autor(a), instituição, ano de publicação e título da tese.

Quadro 1: Distribuição das teses sobre o Programa Saúde na Escola.

\begin{tabular}{|c|c|c|}
\hline Autor(a) & Instituição/ano de publicação & Título \\
\hline CARGNIN, Miria Trentin & $\begin{array}{c}\text { Universidade do Vale do Rio } \\
\text { dos Sinos (Unisinos)/2015 }\end{array}$ & $\begin{array}{c}\text { Programa Saúde na Escola: uma estratégia de } \\
\text { governamento }\end{array}$ \\
\hline SILVA JÚNIOR, Aristides José da & $\begin{array}{c}\text { Universidade Federal de Mato } \\
\text { Grosso (UFMT)/2014 }\end{array}$ & $\begin{array}{c}\text { Programa Saúde na Escola: limites e possibilidades } \\
\text { intersetoriais para o desenvolvimento do autocuidado }\end{array}$ \\
\hline
\end{tabular}

Fonte: Elaboração própria a partir de dados coletados no Portal Capes (2020).

Cargnin (2015), em sua tese, estabeleceu as seguintes questões norteadoras: 1) Como os discursos sobre educação e saúde posicionam a escola? 2) Como tais discursos operam para o governamento dos escolares no PSE? A autora concluiu que o Programa Saúde na Escola é uma estratégia de disseminação de saúde, sobretudo para a população mais vulnerável socialmente.

Esse posicionamento corrobora o Decreto Presidencial que institui o Programa Saúde na Escola, o qual dispõe que dentre os principais objetivos destacam-se: promover a saúde, reforçando a prevenção de agravos à saúde; contribuir para a constituição de condições para a formação integral de educandos; e fortalecer o enfrentamento das vulnerabilidades, no campo da saúde, que possam comprometer o pleno desenvolvimento escolar (Brasil, 2007).

Silva Júnior (2014), em sua tese, estabeleceu o seguinte problema de pesquisa: quais os limites e possibilidades intersetoriais para o desenvolvimento do autocuidado na escola? O autor conclui que a ausência de ações articuladas e integradas entre os gestores dos diversos setores do governo, bem como dos profissionais, acarreta inúmeras limitações como a burocratização dos serviços, o desperdício de tempo, de recursos financeiros e humanos. Além disso, o autor ressalta que a escola pode ser o cenário onde se promove o autocuidado. No entanto, alerta que, para tanto, diversas ações necessitam ser viabilizadas, tais como a valorização e formação dos trabalhadores da saúde e da educação, investimento em infraestrutura, melhoria do acesso aos serviços e assistência à saúde.

Tais alegações são confirmadas por Carvalho (2015, p. 1210), que indica que o PSE se propõe a ser um novo desenho da política de educação e saúde como parte de uma formação ampla para a cidadania, bem como promove a articulação de saberes e a participação de alunos, pais, comunidade escolar e sociedade em geral ao tratar a saúde e educação de forma integral.

O Quadro 2 mostra as nove dissertações encontradas após o refinamento, em que as seguintes informações são exibidas: autor(a), instituição, ano de publicação e título da dissertação. 
Quadro 2: Distribuição das dissertações sobre o Programa Saúde na Escola.

\begin{tabular}{|c|c|c|}
\hline Autor(a) & Instituição/ano de publicação & Título da dissertação \\
\hline BARBIERI, Aline Fabiane & $\begin{array}{l}\text { Universidade Estadual de } \\
\text { Maringá (UEM)/2014 }\end{array}$ & $\begin{array}{l}\text { Análise de políticas públicas brasileiras de educação e } \\
\text { saúde na escola no contexto de crise estrutural do } \\
\text { capital: a função social do Programa Saúde na Escola }\end{array}$ \\
\hline BRESSAN, Fernanda & $\begin{array}{l}\text { Universidade Regional de } \\
\text { Blumenau (FURB)/2014 }\end{array}$ & $\begin{array}{l}\text { O Programa Saúde na Escola: interfaces entre saúde e } \\
\text { educação no município de Blumenau, SC }\end{array}$ \\
\hline BUSS, Patricia & $\begin{array}{c}\text { Universidade Federal de } \\
\text { Santa Catarina (UFSC)/2016 }\end{array}$ & $\begin{array}{l}\text { Os impactos de programas socioeducativos do governo } \\
\text { federal na educação física escolar: do esvaziamento do } \\
\text { conteúdo à virada assistencialista da escola }\end{array}$ \\
\hline CAMPOS, Patricia Lemos & $\begin{array}{l}\text { Universidade Federal de } \\
\text { Uberlândia (UFU)/2014 }\end{array}$ & $\begin{array}{c}\text { Caderneta de saúde do(a) adolescente: uma contribuição } \\
\text { na educação para a sexualidade? }\end{array}$ \\
\hline GOMES, Andreza Legramanti & $\begin{array}{l}\text { Universidade de Santa Cruz } \\
\text { do Sul (Unisc)/2016 }\end{array}$ & $\begin{array}{c}\text { Formação dos trabalhadores de educação e saúde do } \\
\text { Programa Saúde na Escola em um município do Vale do } \\
\text { Rio Pardo }\end{array}$ \\
\hline LODEYRO, Camila Ferrazzo & $\begin{array}{l}\text { Pontifícia Universidade } \\
\text { Católica do Rio Grande do } \\
\text { Sul (PUCRS)/2015 }\end{array}$ & $\begin{array}{c}\text { Programa Saúde na Escola: práticas pedagógicas e } \\
\text { saberes construídos }\end{array}$ \\
\hline MAGALHÃES, Lídia Oliveira & $\begin{array}{l}\text { Universidade Regional } \\
\text { Integrada do Alto Uruguai e } \\
\text { das Missões (URI)/2015 }\end{array}$ & $\begin{array}{l}\text { As ações preventivas e os procedimentos de cuidado } \\
\text { relacionados à saúde desenvolvidos por professores que } \\
\text { atuam com crianças de } 0 \text { a } 6 \text { anos de idade que } \\
\text { frequentam a educação infantil }\end{array}$ \\
\hline SILVA, Leda Terezinha de Freitas & $\begin{array}{l}\text { Universidade de Uberaba } \\
\text { (Uniube) } / 2016\end{array}$ & $\begin{array}{c}\text { Educação e Saúde: Programa Saúde na Escola - } \\
\text { Iturama-MG (2012-2015) }\end{array}$ \\
\hline SILVEIRA, Catharina da Cunha & $\begin{array}{l}\text { Universidade Federal do Rio } \\
\text { Grande do Sul } \\
\text { (UFRGS)/2014 }\end{array}$ & $\begin{array}{l}\text { Escola e docência no Programa Saúde na Escola: uma } \\
\text { análise cultural }\end{array}$ \\
\hline
\end{tabular}

Fonte: Eelaboração própria a partir de dados coletados no Portal Capes (2020).

Na dissertação de Barbieri (2014), encontram-se as seguintes questões norteadoras: 1) De que maneira se configuram as políticas públicas direcionadas à educação e saúde na escola, em âmbito internacional e nacional, na transição do século XX para o XXI? 2) De que modo se processa a influência das agências internacionais na constituição da agenda nacional de políticas públicas de educação e saúde na escola? 3) Que medidas legais foram aprovadas e que principais sujeitos e instituições participaram do processo de construção e elaboração do Programa Saúde na Escola (PSE) no período de 2007 a 2014 ? 4) Nos documentos de políticas analisados, que função social é atribuída à educação e saúde na escola? A autora concluiu que o Programa Saúde na Escola contribui para a garantia dos direitos sociais básicos à saúde e à educação.

Levando isso em consideração, Saviani (2007, p. 1235) já destacava que se pretendia, por meio do PSE, com a colaboração do Ministério da Saúde e das equipes de Saúde da Família, assegurar o atendimento básico a alunos e professores no interior das próprias escolas.

Bressan (2014), em sua dissertação, estabeleceu duas perguntas de pesquisa, quais sejam: 1) Como se deu o processo de implementação do PSE no município de Blumenau, SC? 2) De que maneira os setores da saúde e da educação se articulam para a concretização do PSE no município de Blumenau, SC? A autora, em suas considerações finais, indica que, não obstante ter começado pela área da educação, o PSE, em Blumenal, gradativamente, envolveu a saúde que, mais tarde, foi apontada como 
principal protagonista. No entanto, alertou que tal protagonismo da saúde, em parte, abdicou da parte educativa e possibilitadora de transformações.

A conclusão de Bressan (2014) confirma o posicionamento de Figueiredo, Machado e Abreu (2010, p. 400) em relação às limitações do PSE. Esses autores consideram que, quando pensada numa perspectiva exclusivamente médica e focalizada no controle e prevenção de doenças, a educação em saúde tem sido pouco efetiva para provocar mudanças de atitudes que levem a opções mais saudáveis de vida.

A dissertação de Buss (2016) indica a seguinte questão norteadora: quais os interesses dos programas Mais Educação, Segundo Tempo, Atleta na Escola e Saúde na Escola em relação à escola pública e quais os impactos no componente curricular Educação Física? Para a autora, a forma como o PSE influencia as aulas de Educação Física prejudica o caráter pedagógico do conhecimento a respeito do corpo, tanto em relação às práticas corporais quanto com relação à saúde, que é vista de forma restrita, ao considerar apenas a presença ou ausência de doenças.

A esse respeito, em vez de ações pontuais e isoladas, a melhor contribuição que a saúde poderia oferecer à educação reside na possibilidade de uma ação integrada e articulada, que de maneira crítica e reflexiva possa significar oportunidade de atualização dos educadores, capacitando-os para a tarefa de ministrar o discurso sobre orientação à saúde de forma transversal e interdisciplinar na escola (Figueiredo; Machado; Abreu, 2010, p. 400).

Campos (2014), em sua dissertação, estabeleceu as seguintes questões norteadoras: 1) O que pensam crianças/adolescentes a respeito da Caderneta de Saúde do/a Adolescente distribuída nas escolas participantes do Programa Saúde na Escola - PSE? 2) Qual o efeito das informações da caderneta na vida das crianças/ adolescentes e para o trabalho em sala de aula? 3) O que alunos/crianças/adolescentes do ensino fundamental de escola pública municipal, participantes do Programa PSE, apresentam sobre sexualidade?

Cabe destacar que o PNE 2014-2024 estabeleceu como estratégia a ampliação de programas e o aprofundamento de ações de atendimento ao aluno, em todas as etapas da educação básica, por meio de programas suplementares de material didático-escolar, transporte, alimentação e assistência à saúde (Brasil, 2014). Nesse sentido, identificar os significados atribuídos pelos estudantes a respeito da Caderneta de Saúde do/a adolescente distribuída nas escolas participantes consiste em aprofundar o atendimento ao aluno. Desse modo, a autora concluiu que a sexualidade, nessa caderneta, prioriza a prevenção e os cuidados, inclusive contém discursos de autocuidado e de identidade de gênero que enquadram, disciplinam, regulam e interditam os corpos e comportamentos dos sujeitos (Campos, 2014).

Gomes (2016), em sua dissertação, definiu como problema de pesquisa a seguinte pergunta: como ocorre o processo de formação dos trabalhadores da educação e da saúde que atuam nas Unidade Escolares públicas do Programa Saúde na Escola em um município de médio porte do Vale do Rio Pardo, RS? A autora apontou que o estudo revela que as condições de trabalho a que as entrevistadas estão expostas é a principal limitação das ações realizadas, assim como dos processos de formação de conhecimentos desenvolvidos. Além disso, a autora assevera que as trabalhadoras demandam formação formal para a realização de suas atividades, embora a principal estratégia adotada por essas profissionais é o "aprendizado na prática".

Lodeyro (2015) apontou que o Programa Saúde na Escola é uma estratégia propositiva de comportamentos no sentido de fazer com que o educando desenvolva competências a fim de tornar-se gestor dos riscos de sua saúde, além de multiplicador para a sua família e comunidade. A autora, em sua dissertação, definiu o seguinte problema de pesquisa: as práticas pedagógicas adotadas e saberes construídos no desenvolvimento do PSE promovem mudanças culturais e educacionais junto aos profissionais de educação e educandos envolvidos no programa? A autora concluiu que a disseminação de saúde é facilitada por meio da intersetorialidade educação e saúde.

Nesse aspecto, as ações em saúde previstas no âmbito do PSE, a serem desenvolvidas em articulação com a Saúde e a Educação, deverão considerar a integralidade dos educandos, o que significa garantir a cada um deles o direito à avaliação clínica, 
oftalmológica, auditiva, psicossocial, saúde e higiene bucal, avaliação nutricional, promoção da alimentação saudável, bem como o acesso a ações educativas que lhes garantam educação permanente em saúde, por meio de uma cultura da prevenção no âmbito escolar (Figueiredo; Machado; Abreu, 2010, p. 401).

Magalhães (2015) estabeleceu a seguinte questão norteadora: as ações preventivas e procedimentos de cuidado relacionados à saúde estão presentes nas atividades desenvolvidas por professores que atuam com crianças de 0 a 6 anos de idade que frequentam a educação infantil? A autora, em sua dissertação, alertou que são poucos os educadores que mencionaram que se consideram aptos em relação a conhecimentos relacionados à saúde. No entanto, a autora aponta que houve unanimidade nas narrativas dos professores ao considerarem os saberes relacionados à saúde importantes para a formação do educador infantil.

Silva (2016), em sua dissertação, definiu como problema de pesquisa a seguinte questão: a atuação das áreas de saúde e de educação do Programa Saúde na Escola - PSE possibilita identificar a necessidade de intervenção nos casos de alteração de peso para sobrepeso e obesidade, e a partir de então, preconizar a mudança de hábitos alimentares e correlacionar atividades físicas dos educandos? A autora concluiu que é de fundamental importância a articulação intersetorial a fim de resolver o problema do sobrepeso e da obesidade no contexto escolar, a partir de ações educativas e preventivas de saúde no controle precoce de alterações de peso e de suas consequências na vida dos educandos.

Silveira (2014) estabeleceu as seguintes questões norteadoras: 1) Como o PSE define e investe na escola e na docência para produzir saúde? 2) Que discursos se articulam nesse processo para constituir a escola e a docência? A autora, em sua dissertação, destacou que alunos informados sobre saúde são multiplicadores de hábitos saudáveis em suas famílias e comunidades e concluiu que o Programa Saúde na Escola se mostra comprometido com a garantia e a ampliação da qualidade de vida da população.

Essa interação entre educação e saúde, independentemente de onde ocorre - escola ou serviço de saúde - constitui um caminho importante para a conquista da qualidade de vida (Carvalho, 2015, p. 1208).

O Quadro 3 mostra os dois artigos científicos indexados à plataforma Scielo, após o refinamento por ano de publicação, de 2014 a 2019, área temática (educação), categoria (educação) e tipo de publicação (artigo), em que as seguintes informações são exibidas: autores, periódico, título do artigo científico e ano de publicação.

Quadro3: Distribuição de artigos científicos sobre o Programa Saúde na Escola.

\begin{tabular}{|c|c|c|c|}
\hline Autores & Periódico & Título do artigo científico & $\begin{array}{c}\text { Ano de } \\
\text { publicação }\end{array}$ \\
\hline $\begin{array}{c}\text { FERREIRA, Izabel do Rocio Costa; } \\
\text { MOYSÉS, Samuel Jorge; FRANÇA, } \\
\begin{array}{c}\text { Beatriz Helena Sottile; CARVALHO, Max } \\
\text { Luiz de; MOYSÉS, Simone Tetu. }\end{array}\end{array}$ & $\begin{array}{c}\text { Revista Brasileira de } \\
\text { Educação }\end{array}$ & $\begin{array}{c}\text { Percepções de gestores locais sobre a } \\
\text { intersetorialidade no Programa Saúde } \\
\text { na Escola }\end{array}$ & 2014 \\
\hline $\begin{array}{c}\text { SILVEIRA, Catharina da Cunha; MEYER, } \\
\text { Dagmar Elisabeth Estermann; FÉLIX, } \\
\text { Jeane. }\end{array}$ & $\begin{array}{c}\text { Revista Brasileira de } \\
\text { Estudos Pedagógicos }\end{array}$ & $\begin{array}{c}\text { A generificação da intersetorialidade } \\
\text { no Programa Saúde na Escola }\end{array}$ & 2019 \\
\hline
\end{tabular}

Fonte: Elaboração própria a partir de dados coletados na plataforma Scielo (2021).

O artigo de Ferreira et al. (2014, p. 63), cujo título é "Percepções de gestores locais sobre a intersetorialidade no Programa Saúde na Escola”, publicado na Revista Brasileira de Educação, em 2014, teve como objetivo analisar a percepção de gestores locais do Programa Saúde na Escola sobre a intersetorialidade na condução do referido programa em municípios selecionados. Os autores concluíram que as capacitações são fundamentais para aproximar os atores envolvidos no Programa Saúde na Escola, a fim de qualificar a comunicabilidade e a compreensão dos principais parâmetros do programa. 
Tais considerações vão ao encontro das ações em saúde previstas no âmbito do PSE, que considerarão a atenção, promoção, prevenção e assistência, e serão desenvolvidas articuladamente com a rede de educação pública básica e em conformidade com os princípios e diretrizes do Sistema Único de Saúde (SUS), podendo compreender, entre outras, as seguintes ações: a educação permanente em saúde; a atividade física e saúde; a promoção da cultura da prevenção no âmbito escolar; a inclusão das temáticas de educação em saúde no projeto político-pedagógico das escolas (Brasil, 2007).

O artigo de Silveira, Meyer e Cunha (2019, p. 423), intitulado "A genereficação da intersetorialidade no Programa Saúde na Escola”, publicado na Revista Brasileira de Estudos Pedagógicos, em 2019, teve como objetivo escrutinar os modos pelos quais o trabalho intersetorial é definido, descrito e regulado em documentos normativos e materiais didáticos do Programa Saúde na Escola, para, a partir disso, discutir como o gênero atravessa e dimensiona um de seus princípios organizadores, qual seja, a intersetorialidade.

Os autores argumentam que, no Programa Saúde na Escola, aspectos como "somar esforços", "unir-se" e "articular-se" são mobilizados a fim de propor ações intersetoriais de educação e saúde que demandam esforços adicionais dos profissionais envolvidos sem, no entanto, retribuição devida pelos encargos assumidos.

Dessa maneira, o Programa Saúde na Escola dispõe que o planejamento dessas ações deverá considerar o contexto escolar e social, o diagnóstico local em saúde do escolar e a capacidade operativa em saúde do escolar. No entanto, as potencialidades da ação intersetorial identificadas nos documentos públicos oficiais e descritas nas notícias institucionais sobre o PSE não reverberaram nas práticas dos gestores nem na atuação sobre os territórios (Chiari et al., 2018, p. 11).

\section{Considerações Finais}

A partir do levantamento de teses e dissertações defendidas e de artigos científicos produzidos e publicados de 2014 a 2019, cujo foco foi analisar ações que envolveram o Programa Saúde na Escola, revelou-se o alcance das medidas educacionais tomadas pelo Estado brasileiro para promover a articulação intersetorial entre órgãos e políticas públicas de saúde, e universalizar, mediante articulação entre os órgãos responsáveis pelas áreas da saúde e da educação, o atendimento aos estudantes da rede escolar pública de educação básica por meio de ações de prevenção, promoção e atenção à saúde. O posicionamento foi o de que as considerações apontadas nas dissertações, teses e artigos científicos a respeito do Programa Saúde na Escola podem contribuir para a formação integral e para a qualidade de vida do estudante, bem como pode colaborar com práticas de gestão que levem em consideração as potencialidades das ações intersetoriais previstas nesse programa.

Observou-se, nos artigos científicos, nas teses e dissertações a respeito do Programa Saúde na Escola, algumas temáticas de educação e saúde aplicadas ao contexto escolar, tais como o autocuidado, a sexualidade, a atividade física, a nutrição de educandos, bem como considerações atinentes à ausência de saberes relacionados à saúde na formação docente.

No entanto, esta pesquisa revelou também a escassez de estudos científicos a respeito de pesquisas, sobretudo longitudinais, sobre as diferentes ações dispostas no Decreto que institui o Programa Saúde na Escola (Brasil, 2007), quais sejam: avaliação clínica; avaliação nutricional; promoção da alimentação saudável; avaliação oftalmológica; avaliação da saúde e higiene bucal; avaliação auditiva; avaliação psicossocial; atualização e controle do calendário vacinal; redução da morbimortalidade por acidentes e violências; prevenção e redução do consumo do álcool; prevenção do uso de drogas; promoção da saúde sexual e da saúde reprodutiva; controle do tabagismo e outros fatores de risco de câncer; educação permanente em saúde; atividade física e saúde; promoção da cultura da prevenção no âmbito escolar; inclusão das temáticas de educação em saúde no projeto político pedagógico das escolas.

Diante da escassez de estudos científicos publicados a respeito do Programa Saúde na Escola, sobretudo na área de educação, sugere-se, adicionalmente, a utilização desta pesquisa para subsidiar novas investigações. Assim, recomenda-se, como ações futuras, estudos com desenhos longitudinais que analisem as influências das ações intersetoriais de educação e saúde na 
qualidade de vida dos estudantes.

\section{Referências}

Barbieri, A. F. (2014). Análise de políticas públicas brasileiras de educação e saúde na escola no contexto de crise estrutural do capital: a função social do Programa Saúde na Escola. Dissertação (Mestrado em Educação). Universidade Estadual de Maringá, Maringá, PR.

Bressan, F. (2014). O Programa Saúde na Escola: interfaces entre saúde e educação no município de Blumenau, SC. Dissertação (Mestrado em Educação). Universidade Regional de Blumenau, Blumenal, SC.

Brasil (2019). Constituição da República Federativa do Brasil de 1988. Diário Oficial da União - Seção 1 - 5/10/1988,

Brasil (1996). Lei n ${ }^{\text {9.394, de }} 20$ de dezembro de 1996. Estabelece as diretrizes e bases da educação nacional. Diário Oficial da União - Seção 1 - 23/12/1996, Página 27833 (Publicação Original).

Brasil (2007). Decreto no 6.286, de 5 de dezembro de 2007. Institui o Programa Saúde na Escola - PSE, e dá outras providências. Diário Oficial da União $06 / 12 / 2007$, p. 2.

Brasil (2014). Lei no 13.005, de 25 de junho de 2014. Aprova o Plano Nacional de Educação - PNE e dá outras providências. Diário Oficial da União - Seção 1 - Edição Extra - 26/6/2014, Página 1 (Publicação Original).

Buss, P. (2016). Os impactos de programas socioeducativos do governo federal na educação física escolar: do esvaziamento do conteúdo à virada assistencialista da escola. Dissertação (Mestrado em Educação). Universidade Federal de Santa Catarina.

Campos, P. L. (2014). Caderneta de saúde do(a) adolescente: uma contribuição na educação para a sexualidade? Dissertação (Mestrado em Educação). Universidade Federal de Uberlândia.

Carvalho, F. F. B. (2015). A saúde vai à escola: a promoção da saúde em práticas pedagógicas. Physis, 25(4), 1207-1227.

Cargnin, M. T. (2015). Programa Saúde na Escola: uma estratégia de governamento. Tese (Doutorado em Educação). Universidade do Vale do Rio dos Sinos, São Leopoldo, RS.

Chiari, A. P. G., Ferreira, R. C., Akerman, M., Amaral, J. H. L., Machado, K. M., \& Senna, M. I. B. (2018). Rede intersetorial do Programa Saúde na Escola: sujeitos, percepções e práticas. Cadernos de Saúde Pública, 34(5), e00104217.

Creswell, J. W (2007). Projeto de pesquisa: métodos qualitativo, quantitativo e misto. Tradução: Luciana de Oliveira Rocha. (2a ed.), Artmed.

Ferreira, I. R. C., Moysés, S. J., França, B. H. S., Carvalho, M. L., \& Moysés, S, T. (2014). Percepções de gestores locais sobre a intersetorialidade no Programa Saúde na Escola. Revista Brasileira de Educação. 19(56).

Figaro, R. (2014). A triangulação metodológica em pesquisas sobre a Comunicação no mundo do trabalho. Revista Fronteiras - estudos midiáticos. 16(2), 124131.

Figueiredo, T. A. M., Machado, V. L. T., \& Abreu, M. M. S. (2010). A saúde na escola: um breve resgate histórico. Ciência \& Saúde Coletiva, 15(2), 397-402.

Gomes, A. L. (2016). Formação dos trabalhadores de educação e saúde do Programa Saúde na Escola em um município do Vale do Rio Pardo. Dissertação (Mestrado em Educação). Universidade de Santa Cruz do Sul.

Libâneo, J. C. (2016). Políticas educacionais no Brasil: desfiguramento da escola e do conhecimento escolar. Cadernos de Pesquisa, 46(159), 38-62.

Lodeyro, C. F. (2019). Programa Saúde na Escola: práticas pedagógicas e saberes construídos. Dissertação (Mestrado em Educação). Pontifícia Universidade Católica do Rio Grande Do Sul.

Magalhães, L. O. (2015). As ações preventivas e os procedimentos de cuidado relacionados à saúde desenvolvidos por professores que atuam com crianças de 0 a 6 anos de idade que frequentam a educação infantil. Dissertação (Mestrado em Educação). Universidade Regional Integrada do Alto Uruguai e das Missões, Frederico Westphalen, RS.

Saviani, D. (2007). O Plano de desenvolvimento da educação: análise do projeto do MEC. Educação \& Sociedade. 28(100), 1231-1255.

Saviani, D. (2008). Política educacional brasileira: limites e perspectivas. Revista de Educação PUC-Campinas, 24, 7-16.

Saviani, D. (2013). A educação na Constituição Federal de 1988: avanços no texto e sua neutralização no contexto dos 25 anos de vigência. RBPAE, 29(2), 207221 .

Silva, L. T. F. (2016). Educação e Saúde: Programa Saúde na Escola - Iturama-MG (2012-2015). Dissertação (Mestrado em Educação). Universidade de Uberaba.

Silva Júnior, A. J. (2014). Programa Saúde na Escola: limites e possibilidades intersetoriais para o desenvolvimento do autocuidado. Tese (Doutorado em Educação). Universidade Federal de Mato Grosso.

Silveira, C. C. (2014). Escola e docência no Programa Saúde na Escola: uma análise cultural. Dissertação (Mestrado em Educação). Universidade Federal do Rio Grande do Sul.

Silveira, C. C., Meyer, D. E. E., \& Félix, J. (2019). A generificação da intersetorialidade no Programa Saúde na Escola. Revista Brasileira de Estudos Pedagógicos. 100(255). 